International Journal of Biology, Pharmacy and Allied Sciences (IJBPAS) 'A Bridge Betuen Caboratory and QRendo' WWW.jibpas.com

\title{
ROLE OF TISSUE, SERUM AND SALIVARY MICRO RNA 21 IN ORAL POTENTIALLY MALIGNANT DISORDERS AND ORAL CARCINOMA-A SYSTEMATIC REVIEW
}

\section{UMA MAHESWARI TN ${ }^{1 *}$ AND SWATHI KV ${ }^{2}$}

1: Professor, Head of administration and Research scholar, Department of Oral Medicine and Radiology, Saveetha Dental College, Saveetha University, 162 Poonamallee High Road, Vellapan Chavadi, Chennai-600 077

2: PG Student, Department of Oral Medicine and Radiology, Saveetha Dental College, Saveetha University, 162 Poonamallee High Road, Vellapan Chavadi, Chennai-600 077

*Corresponding Author: T.N. Uma Maheswari: E Mail: umasamsi@gmail.com; Phone: 9840958339

Received 26 ${ }^{\text {th }}$ March 2020; Revised $16^{\text {th }}$ April 2020; Accepted $8^{\text {th }}$ July 2020; Available online $1^{\text {st }}$ Jan. 2021 https://doi.org/10.31032/IJBPAS/2021/10.1.5287

\section{ABSTRACT}

\section{BACKGROUND}

Micro RNA's (miRNAs) are small non- coding RNA's which aid in cellular proliferation, differentiation and apoptosis. They act as post transcriptional modifiers by binding to target m RNA's and deregulation of certain miRNA's contributes to an increased expression of an oncogene or tumour suppressor gene [1]. The possible ways of the mechanisms of miRNA include Cap-40S initiation inhibition, 60S Ribosomal unit joining inhibition, elongation inhibition, ribosome drop-off (premature termination),co-translational nascent protein degradation, sequestration in P-bodies, mRNA decay (destabilisation), mRNA cleavage, transcriptional inhibition through miRNA-mediated chromatin reorganization followed by gene silencing [2]. Synergistic deregulation of multiple miRNAs and their protein coding counterparts aids in tumorigenesis. MiRNA was originally discovered in Caenorhabditis elegans, which is a free-living transparent nematode (roundworm), about $1 \mathrm{~mm}$ in length that lives in temperate soil environments [3]. This present systematic review aims in evaluation of 
the role of miRNA21 as a potent diagnostic marker in tissue, serum and salivary samples of Oral Potentially Malignant Disorders (OPMD) and Oral carcinoma.

\section{MATERIALS AND METHOD}

The search was done using the MeSH terms in the electronic data base namely PubMed data base, Google scholar. A total of 82 articles were retrieved. On application of the inclusion and exclusion criteria finally 16 studies were included in the Systematic Review.

\section{RESULTS}

A total of185 OPMD cases, 16 beningn neoplasms (7-Pleomorphic Adenomas, 9-Warthin's tumour), 270 malignant neoplasms, 117 healthy control cases, 20 disease control cases (Recurrent Aphthous Stomatitis) were analysed for the expression of salivary, serum and tissue miRNA21.After the analysis of all the included studies, thirteen studies were found in tissue miRNA 21 of which eight studies were exclusively of tissue miRNA 21 . Out of the three studies for serum miRNA 21, only one study was found to be exclusively done on serum miRNA 21 . Likewise with three studies on salivary miRNA 21 , only one study was found to be exclusive for salivary miRNA 21. Quality assessment of the sixteen studies were done using QUADAS 2 tool and further risk of bias chart and applicability concern were obtained using Revman 5.3 software which proved that studies done by by, Cervigne et al (2009), Danielsson et al (2012), Tseng et al (2017), Wen HaoRen et al (2014) and Zahran et al (2015) had low risk of bias while studies done by Cinpolat et al(2017), Hung et al(2016), Volker Gassling et al (2017), Wang et al (2015) had moderate risk of bias. Studies done by Coutinho-Camillo et al (2015), Gao et al (2017) and another study by Wen HaoRen et al (2014) were unclear in their risk of bias and applicability concern. Studies done by Elisabeth Nylander et al (2012), Zhu et al (2015), Patricia et al (2010), Zheng et al (2016) had high risk of bias.

\section{CONCLUSION}

MiRNA 21 mainly targets the tumour suppressor genes and affects the process of carcinogenesis. This systematic review proves that most of the included studies reveal an upregulation of miRNA 21 in OPMD and OSCC and identification of miRNA 21 in saliva, tissue and serum samples in OPMD can thus serve as an early diagnostic marker before it progresses to carcinoma. Based on the statistical analysis of sensitivity, specificity, ROC it was found that one study on tissue miRNA21 had ROC of 0.74 , a study on serum miRNA 21 had ROC of 0.788 and study on salivary miRNA 21 revealed an ROC of 0.73 .On taking into account the ROC of the included studies it was found to be consistent with an average of 0.75 which indicates that serum, tissue and saliva all are consistent and they serve as 
optimal media for the identification of miRNA 21 and even other miRNAs in cases of OPMD and OSCC. Since collection of saliva is a non invasive method compared to serum or tissue, this systematic review proves that saliva is a surrogate marker for the identification of miRNA 21 in OPMD and oral cancer.

Keywords: SalivarymiRNA 21, tissue miRNA 21, serum miRNA 21, Oral Potentially

\section{Malignant Disorders}

\section{BACKGROUND}

Victor Ambro's and Gary Ruvkun were the pioneers who first discovered Lin-4,a miRNA.Lin-4 was found to be a heterochronic gene controlling the temporal development of all larval stages in C.elegans [4]. Ambros, along with Rosalind Lee and Rhonda Feinbaum found that a 700bp fragment could contain this lin-4 gene but could not find the conventional start and stop codons. Inan other study led by Ruvkun and his colleagues, it was found that Lin-14 gene was downregulated at a posttranscriptional level and lin-14 3'UTR region was sufficient for temporal regulation which made Victor Ambros and Ruvkun to conclude that the small and non-protein coding transcript lin-4 regulates lin-14 through its 3'UTR region [5]. In 2000, Reinhart and his team discovered let-7, which was also a hetreochronic gene of C.elegans and was a $21 \mathrm{nt}$ RNA controlling L4-to-adult transition of larval development. These were the initial steps which led to the discovery of numerous mi RNA's [6].
The role of miRNAs in cancer was first discovered in 2002.MiRNA-15 \&16 located at chromosome $13 \mathrm{q} 14$, a region frequently deleted in Chronic Lymphocytic Leukemia (CLL). These genes were found to be deleted or downregulated in $60 \%$ of B-cell CLL, which suggested that these genes behaved as tumour suppressors in CLL. In 2005, Johnson et al., [7] reported the first miR-target interaction with relevance to cancer. They demonstrated that in C. elegans let-7 targets let-60, encoding the $C$. elegans ortholog of human oncogene RAS and found that human RAS expression is regulated by let-7 in cell culture. In 2010 Medina et al., reported the results on mice that conditionally overexpressed miRNA21 which suggested that the overexpression of a single miRNA, specifically miRNA21, was sufficient to cause tumor development. It was also found that the tumour volume and survival were dependent on miRNA 21 overexpression and if miRNA21 was inactivated, tumour was found to be regressing in size [8]. This deregulation of miRNAs were caused by several 
mechanisms like deletion, amplification, mutation or dysregulation of transcription factors that target specific miRNAs and also controlled by epigenetic mechanisms [9].

The role of miRNAs as metastatic activators was first reported by $\mathrm{Ma}$ et al and they found that in vitro miRNA10b, positively regulated cell migration and invasion and were capable of initiating tumor invasion and metastasis in vivo. MiRNA10b targeted HOXD10 which was a transcriptional repressor of RHOC, a key player in metastasis. Concordantly, miRNA10b expression was found to be elevated in about $50 \%$ of metastatic breast tumors compared with metastasis-free tumors or normal breast tissues [10].

It was also found that miRNAs can prevent tumor metastasis. A study conducted by Tavazoie et al. found that in patients with breast cancer there with low expression levels of miRNA 335, miRNA 126 and miRNA206 had a shorter median time to metastatic relapse. Restoration of their expression in breast cancer cell lines decreased number of metastasis in inoculated mice. These miRNAs were found to have distinct mechanisms for metastasis suppression and was found that restoration of miRNA126 expression significantly suppressed overall tumor growth; while restoration of miRNA 335 or miRNA206 levels altered cells morphology, possibly causing a decrease in cell motility [11].

MiRNA plays an important role in cellular growth, differentiation, apoptosis and immune response, while some miRNA aids in tumour suppression [12]. During development of malignancy some miRNA are up regulated while some are down regulated, any change in the expression of miRNA can cause tumour suppression and act as carcinogens [13]. miRNA have been isolated in tissues. Tissue-specific miRNAs (TS miRNA) specifically expressed in particular tissues play an important role in tissue identity, differentiation and function. These tissue miRNAs, exhibit tissuespecific or developmental-stage-specific expression pattern and play an important role in maintaining tissue identity and function They have been associated with various diseases such as cardiovascular disease, diabetes and cancer [14]. Likewise miRNA expressions were also seen in serum. Serum miRNAs are relatively stable at variable $\mathrm{pH}$ conditions, resistant to repeated freeze thaw and enzymatic degradation, which make them as a suitable biomarker [15]. Saliva is a biological fluid which serves as a diagnostic tool in health and disease and it contain a wide spectrum of proteins/ peptides, nucleic acids, electrolytes, and hormones that originate from multiple local and systemic sources [16]. Saliva contains 
various exosomes contain lipids, mRNA, microRNA, DNA and proteins of which miRNA is a promising marker [17].

MiRNA21 is a relatively new member of the oncogenic miRNA group. Initially it was found to be over expressed in human glioblastoma tumors, miRNA21 was described as an anti-apoptotic factor predicted to down regulate genes associated with advancing apoptosis. The target sites for miRNA21 in general include ANP32A (Acidic leucine-rich nuclear phosphorprotein 32 family member A), BTG2 (Bcell translocation gene 2) $\quad \mathrm{Bcl} 2$ (B-cell lymphoma2), P12/CDK2AP1 (Cyclindependent kinase 2-associated protein 1) HNRPK (Heterogeneous nuclear ribonucleoprotein $\quad \mathrm{K}), \quad \mathrm{IL}-12 \mathrm{p} 35$ (Interleukin 12), JAG1 (Jagged1), MEF2C (Myocyte-specific enhancer factor 2C), hMSH2 (MutS protein homolog 2), PDCD4 (Programmed cell death protein 4), PTEN (Phosphatase and tensin homolog (PTEN), RECK (Reversion-inducing-cysteine-rich protein with kazal motifs), RhoB (Ras homolog gene family, member B), SMARCA4 (Transcription activator BRG1 also known as ATP-dependent helicase SMARCA4), TGFBRII (Transforming growth factor, beta receptor II), SPRY1 (Protein sprouty homolog 1), SPRY2 (Sprouty homolog 2), TP63 (Tumor protein p63) and Tropomyosin [18]. BCL2, CASP2, CASP7, CASP8, DIABLO are the important target genes for miRNA 21 in OSCC.

In this systematic review the studies done in salivary, tissue and serum miRNA 21 as biomarkers for OPMD transforming to malignancy and in oral cancer are included. Search for deregulation of salivary miRNA in literature review in OPMD and oral carcinoma is scanty, hence this Systematic review focuses on identifying the lacunae in existing studies to improvise the future research on tissue, serum, salivary miRNA to evaluate the role of miRNA 21 in detection of early malignancy in OPMD.

\subsection{AIM \& OBJECTIVES}

- To evaluate the existing literature, if tissue, serum and salivary miRNA 21 serves as viable markers in detecting early malignancy in OPMD

- To analyse whether miRNA21 is upregulated or down regulated in OPMD and oral carcinoma.

- To analyse the sensitivity and specificity of miRNA 21 in tissue, serum and saliva to evaluate which is most potential in detecting early dysplastic changes in OPMD.

\section{METHODS}

\subsection{LITERATURE SEARCH}

The search engines used in this Systematic Review using MeSH terms were PubMed data base and Google scholar. The search 
was done in the studies in the last 5 years. $\mathrm{MeSH}$ terms for key words like leukoplakia, oral submucous fibrosis and oral lichen planus along with the salivary, tissue and serum miRNA21 and malignant transformation were used to retrieve studies on salivary ,tissue and serum miRNA 21 in OPMD and Oral Cancer.

\subsection{SELECTION CRITERIA}

\subsubsection{INCLUSION CRITERIA}

1. Studies on expression of salivary, tissue and serum miRNA 21 in OPMD.

2. Studies on expression of salivary, tissue and serum miRNA 21 in Oral Cancer.

3. Studies on expression of miRNA 21 in a combination of tissues/ serum/ saliva and cell lines of OPMD and Oral Cancer.

\subsubsection{EXCLUSION CRITERIA}

1. Studies done in carcinoma other than the oral carcinoma were excluded

2. Animal studies.

3. Studies on the expression of miRNA 21 exclusively done in human cell culture lines.

Around eighty two articles where identified from web search .After applying human filter, still eighty two articles were retained. Thirty two articles were obtained after screening the title. Twenty one articles were excluded after applying the inclusion and exclusion criteria. Five articles were obtained from Google scholar. From the obtained sixteen articles, nine were done exclusively in tissue miRNA 21 , one in serum miRNA 21 , one in salivary miRNA 21 , one in the combination of tissue, serum, salivary miRNA 21 , one in the combination of salivary and tissue miRNA 21 and three done in the combination of cell line and tissues in the samples OPMD and Oral cancer were included in this Systematic Review (Figure 1).

\subsection{QUALITY ASSESSMENT OF THE STUDIES}

These sixteen articles were assessed for their quality using QUADAS tool2. Quality assessment of diagnostic accuracy studies, has four domains namely patient sampling, index test, reference standard and flow and timing. Each of this domain consist of two to four questions which were answered as "yes", "no" or "unclear". This data was fed into Review manager software namely in Revman 5.3 to obtain a colour coded chart of risk of bias and applicability concern (Figure 2).

\subsection{DATA EXTRACTION}

Studies selected were evaluated by two reviewers after a data extraction table was developed. It captured the following details like year of study, number of samples and group methodology for evaluation of micro RNA, the place of study, mean and standard deviation, cut off value, sensitivity 
and specificity and details related to statistical analysis.

\subsection{DATA SYNTHESIS}

As the studies were heterogeneous and there were missing data the results of the studies could not be combined and analysed by meta analysis.

\section{RESULTS}

\subsection{LITERATURE EVALUATION}

The total number of samples analysed for expression of miRNAs in each of OPMD and Oral Cancer is illustrated in Figure 4. Of the sixteen studies, four studies were done in OPMD, eight studies in Oral cancer and three studies in a combination of OPMD and Oral cancer,

\subsection{RISK OF BIAS AND APPLICABILITY CONCERN}

Studies done by Cervigne et al (2009), Danielsson et al (2012), Tseng et al (2017), Wen HaoRen et al (2014) and Zahran et al (2015) had low risk of bias, while studies done by Cinpolat et al (2017), Hung et al (2016), Volker Gassling et al (2017), Wang et al (2015) had moderate risk of bias. Studies done by Coutinho-Camillo et al (2015), Gao et al (2017), Ren et al (2014) were unclear in their risk of bias and applicability concern. Studies done by Elisabeth Nylander et al (2012), Patricia et al (2010), Zhu et al (2015), Zheng et al (2016) had high risk of bias. These studies revealed the upregulation of miRNA 21 in many cases of OPMD and OSCC except two studies done by Cinpolat et al (2017), Wang et al (2015) revealed the down regulation of miRNA21. Three studies by Ren et al (2014), Hung et al (2016), Zahran et al (2015) revealed statistically significant AUC ie., 0.788, 0.74,0.73 respectively indicating the need for further focusing on these markers in varied populations in varied dysplastic cases of OPMD and OSCC (Figure 5). 
82 articles identified by key word search

HUMAN FILTER APPLIED

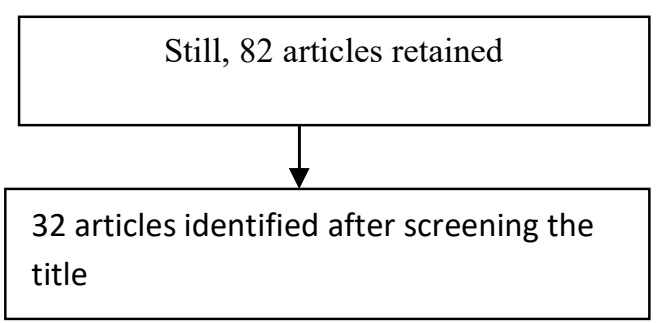

$\underline{21 \text { articles excluded according to inclusion and exclusion criteria }}$

2-Excluded as they were not clinical trials

1-Excluded as it was not done in oral cancer

18-Excluded as they were done only in human cell culture lines

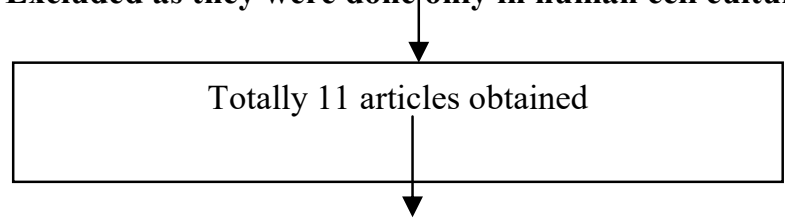

5 articles were identified from Google Scholar

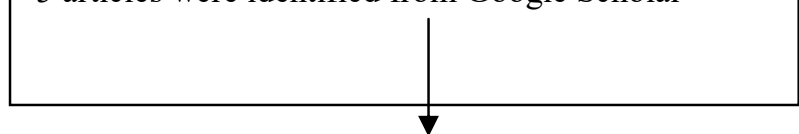

Totally, 16 articles were chosen as they included studies done on miRNA 21 in tissue,serum and saliva samples of OPMD and Oral cancer

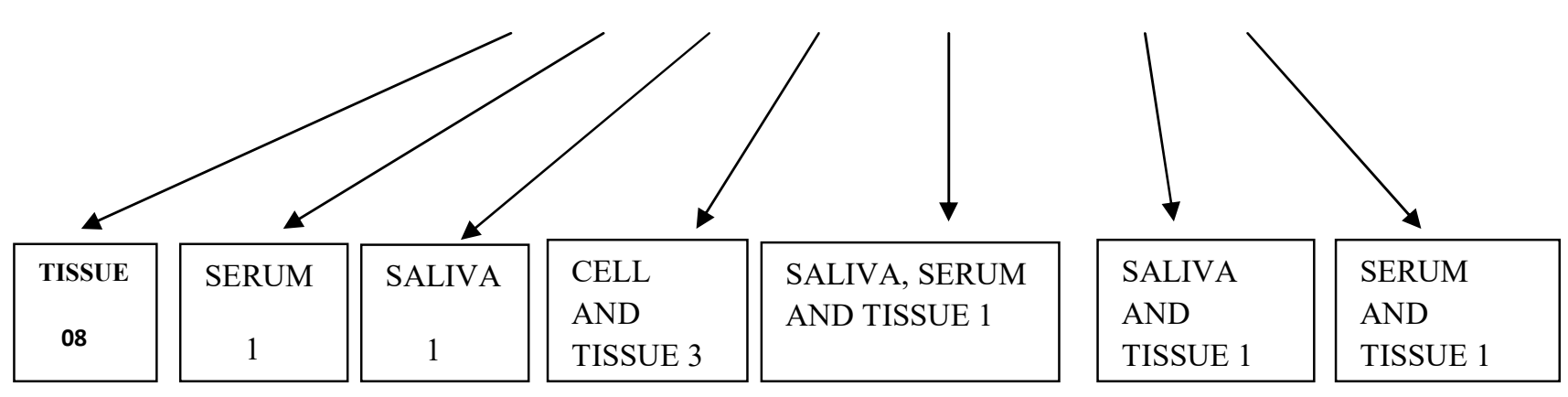

Figure 1: Prisma flow chart for selection of studies 


\begin{tabular}{|c|c|c|c|c|c|c|c|}
\hline $\begin{array}{l}\text { AUTHOUR, } \\
\text { JOURNAL } \\
\text { YEAR AND } \\
\text { COUNTRY }\end{array}$ & $\begin{array}{l}\text { Other } \\
\text { MiRNAs } \\
\text { Seen }\end{array}$ & $\begin{array}{c}\text { TYPE OF } \\
\text { ORAL LESION } \\
\text { AND SAMPLE } \\
\text { DISTRIBUTIO } \\
\mathbf{N}\end{array}$ & $\begin{array}{c}\text { SAMPLE } \\
\text { COLLECTION }\end{array}$ & $\begin{array}{c}\text { METHODOLOG } \\
Y\end{array}$ & $\begin{array}{c}\text { UP/DOWN } \\
\text { REGULAT } \\
\text { ED }\end{array}$ & $\begin{array}{l}\text { SENSITIV } \\
\text { ITY,SPEC } \\
\text { IFICITY, } \\
\text { ROC }\end{array}$ & CONCLUSION \\
\hline $\begin{array}{c}\text { Nilva. k. Cervigne et } \\
\text { al, Human Molecular } \\
\text { Genetics,2009 } \\
\text { University of } \\
\text { Toronto,Canada }\end{array}$ & $\begin{array}{l}\text { miRNA 181b } \\
\quad 345\end{array}$ & $\begin{array}{l}\text { Leukoplakia, } \\
\text { OSCC } \\
\text { 22-progessive } \\
\text { leukoplakia } \\
7-\text { non } \\
\text { progressive } \\
\text { leukoplakia } \\
\text { 14-oscc }\end{array}$ & $\begin{array}{c}\text { Biopsy } \\
\text { done.FFPE and } \\
\text { fresh frozen } \\
\text { specimens were } \\
\text { used }\end{array}$ & $\begin{array}{l}\text { RNA extracted } \\
\text { from QRT-PCR } \\
\text { Taq Man low } \\
\text { density assay }\end{array}$ & $\begin{array}{c}\text { Up } \\
\text { regulated }\end{array}$ & $\begin{array}{c}\text { Not } \\
\text { mentioned }\end{array}$ & $\begin{array}{l}\text { Over-expression of miRNA21, } \\
\text { MiRNA 181b and miRNA } 345 \\
\text { suggested their important role } \\
\text { in malignant transformation }\end{array}$ \\
\hline $\begin{array}{l}\text { Guanghui Zhu et } \\
\text { al.,Biomed } \\
\text { Research,2015 } \\
\text { Shangai,China }\end{array}$ & $\begin{array}{l}\text { miRNA } \\
499,205\end{array}$ & $\begin{array}{c}\text { Oral } \\
\text { leukoplakia } \\
\text { Healthy control- } \\
5 \\
\text { Oral } \\
\text { leukoplakia-20 } \\
\text { Mt oral } \\
\text { leukoplakia-5 }\end{array}$ & Not mentioned & Not mentioned & $\begin{array}{c}\text { miRNA 21- } \\
\text { upregulated } \\
\text {, miRNA } \\
499 \\
\text { downregulat } \\
\text { ed, miRNA } \\
\text { 205- } \\
\text { upregulated }\end{array}$ & $\begin{array}{c}\text { Not } \\
\text { mentioned }\end{array}$ & $\begin{array}{c}\text { Key genes that play crucial roles in } \\
\text { the malignant transformation of oral } \\
\text { leukoplakia to oral cancer i.e hub } \\
\text { genes (STAT5B, EGFR, PDGFRB, STAT5A), } \\
5 \text { intra-MAOC genes } \\
\text { (RAF1, PDGFRB, SRC, PRKACA, EGFR), } 5 \\
\text { inter-MAOC genes } \\
\text { (PRKCA, MAPK1, MAPK3, ESR1, FYN) and } \\
\text { 8 miRNAs (hsa-miRNA-499-5p, 549, } \\
\text { 205, 525-5p, 21, 323-3p, 423-3p, } \\
\text { 491-3p) were identified. } \\
\end{array}$ \\
\hline $\begin{array}{c}\text { Tseng et } \\
\text { al.,Anticancer } \\
\text { Research,2017 } \\
\text { Kaohsiung, Taiwan }\end{array}$ & $\begin{array}{l}\text { Other miRNAs } \\
\text { not specified }\end{array}$ & $\begin{array}{c}\text { OSCC } \\
95 \text { OSCC tissue } \\
\text { samples }\end{array}$ & Not mentioned & $\begin{array}{l}\text { stem-loop real- } \\
\text { time polymerase } \\
\text { chain reaction }\end{array}$ & $\begin{array}{c}\text { Up } \\
\text { regulated }\end{array}$ & $\begin{array}{c}\text { Not } \\
\text { mentioned }\end{array}$ & $\begin{array}{c}\text { miRNA 21-3p plays a crucial } \\
\text { oncogenic role in cell metastasis } \\
\text { during } \\
\text { OSCC progression. }\end{array}$ \\
\hline $\begin{array}{c}\text { Gao et } \\
\text { al.,2017,Molecular } \\
\text { Carcinogenesis, Qingd } \\
\text { ao, Shandong, China. }\end{array}$ & Nil & $\begin{array}{c}\text { OSCC } \\
\text { Not mentioned }\end{array}$ & Not mentioned & Not mentioned & $\begin{array}{c}\text { Up } \\
\text { regulated }\end{array}$ & $\begin{array}{c}\text { Not } \\
\text { mentioned }\end{array}$ & $\begin{array}{l}\text { PTENp1 was aberrantly expressed } \\
\text { in OSCC. There was a positive } \\
\text { correlation between the expression } \\
\text { levels of PTENp1 and PTEN. } \\
\text { PTENp1 acted as a competing } \\
\text { endogenousRNA that protects PTEN } \\
\text { transcripts from being inhibited by } \\
\text { miRNA } 21 .\end{array}$ \\
\hline $\begin{array}{c}\text { Coutinho-Camillo et } \\
\text { al.,2015,Cancer } \\
\text { Genetics,SaoPaulo,Br } \\
\text { azil }\end{array}$ & $\begin{array}{c}\text { miRNA-15a,16, } \\
\text { 17-5p,20a, } \\
29 \mathrm{a}, 34 \mathrm{a}\end{array}$ & $\begin{array}{c}\text { OSCC } \\
20 \text { OSCC and } 5 \\
\text { normal oral } \\
\text { mucosa tissue } \\
\text { samples }\end{array}$ & Not mentioned. & $\begin{array}{l}\text { Real time RT- } \\
\text { PCR }\end{array}$ & $\begin{array}{c}\text { Downregula } \\
\text { tion of } \\
\text { miRNA-15a, } \\
29 \mathrm{a}, 34 \mathrm{a} \text { in } \\
50,75 \text {, and } \\
70 \% \text { of } \\
\text { samples, } \\
\text { respectively. } \\
\text { miRNA-16, } \\
17-5 p,-20 a, \\
-21 \\
\text { expression }\end{array}$ & $\begin{array}{c}\text { Not } \\
\text { mentioned }\end{array}$ & $\begin{array}{l}\text { Alterations in the expression of } \\
\text { apoptosis-regulating miRNAs and } \\
\text { genes in the apoptotic pathway, demonstrating } \\
\text { that regulation of } \\
\text { apoptosis is a hallmark } \\
\text { of OSCC pathogenesis }\end{array}$ \\
\hline
\end{tabular}




\begin{tabular}{|c|c|c|c|c|c|c|c|}
\hline & & & & & $\begin{array}{l}\text { was normal } \\
\text { in } 80,75,90 \text {, } \\
\text { and } 60 \% \text { of } \\
\text { samples, } \\
\text { respectively. }\end{array}$ & & \\
\hline $\begin{array}{c}\text { Wang et } \\
\text { al.,2015,Molecular } \\
\text { Biology Reports,China }\end{array}$ & Nil & $\begin{array}{c}\text { OSCC } \\
10 \text { pairs of } \\
\text { OSCC and } \\
\text { noncancerous } \\
\text { tissue samples. }\end{array}$ & Not mentioned & RT-PCR & $\begin{array}{c}\text { Down } \\
\text { regulated }\end{array}$ & $\begin{array}{c}\text { Not } \\
\text { mentioned }\end{array}$ & $\begin{array}{c}\text { Combination of cisplatin application } \\
\text { with miRNA21 downregulation } \\
\text { might be a potential strategy for the } \\
\text { treatment of human OSCC }\end{array}$ \\
\hline $\begin{array}{l}\text { Danielsson et al., } \\
\text { 2012,Journal of Oral } \\
\text { Pathology and } \\
\text { Medicine }\end{array}$ & $\begin{array}{c}\text { miRNA- 125b, } \\
203\end{array}$ & $\begin{array}{l}\text { OLP } \\
20 \text { patients with } \\
\text { OLP and } 20 \\
\text { age- and sex- } \\
\text { matched healthy } \\
\text { controls }\end{array}$ & $\begin{array}{l}\text { In biopsies from } \\
20 \text { patients with } \\
\text { OLP and } 20 \text { age- } \\
\text { and sex-matched } \\
\text { healthy controls, } \\
\text { epithelium was } \\
\text { laser dissected } \\
\text { and analyzed }\end{array}$ & qRT/PCR. & $\begin{array}{c}\text { Increased } \\
\text { expression } \\
\text { of miRNA } \\
21 \text { and } \\
\text { miRNA203, } \\
\text { decreased } \\
\text { expression } \\
\text { of } \\
\text { miRNA125 }\end{array}$ & $\begin{array}{c}\text { Not } \\
\text { mentioned }\end{array}$ & $\begin{array}{l}\text { When comparing microRNA } \\
\text { expression to levels of p53 and p63 } \\
\text { RNA, a significant negative } \\
\text { correlation was seen between } \Delta \text { Np63 and } \\
\text { miRNA } 203 \text { and between miRNA21 } \\
\text { and p53, respectively. }\end{array}$ \\
\hline $\begin{array}{l}\text { Volker Gassling et } \\
\text { al.,2013,Plos } \\
\text { One,Germany }\end{array}$ & $\begin{array}{c}\text { miRNA -31, } \\
155,130 b, 223\end{array}$ & $\begin{array}{c}\text { OLP } \\
\text { OLP-7 } \\
\text { Healthy control- } \\
7\end{array}$ & $\begin{array}{c}\text { Native tissue } \\
\text { samples were } \\
\text { collected from } \\
\text { the oral mucosa } \\
\text { of seven patients } \\
\text { with OLP. The } \\
\text { control group } \\
\text { was composed of } \\
\text { native tissue from } \\
\text { elective oral } \\
\text { surgery. }\end{array}$ & $\begin{array}{c}\text { Affymetrix } \\
\text { Human Gene } 1.0 \\
\text { ST } \\
\text { Array while } \\
\text { miRNA profiling } \\
\text { was performed } \\
\text { using the } \\
\text { microRNA } \\
\text { Galaxy Array }\end{array}$ & $\begin{array}{l}\text { miRNA -21, } \\
31,155, \\
130 \mathrm{~b}, 223 \\
\text { were } \\
\text { upregulated }\end{array}$ & $\begin{array}{c}\text { Not } \\
\text { mentioned }\end{array}$ & $\begin{array}{c}\text { miRNA associated with transcripts } \\
\text { which are regulated when comparing OLP } \\
\text { patients with healthy control } \\
\text { individuals. This suggests that } \\
\text { miRNAs may potentially regulate } \\
\text { disease-relevant transcripts, } \\
\text { proposing the concept of therapeutic } \\
\text { interventions based on miRNAs }\end{array}$ \\
\hline
\end{tabular}

\begin{tabular}{|c|c|c|c|c|c|c|c|}
\hline $\begin{array}{l}\text { AUTHOUR, } \\
\text { YEAR AND } \\
\text { COUNTRY }\end{array}$ & $\begin{array}{l}\text { Other } \\
\text { miRNA }\end{array}$ & $\begin{array}{c}\text { TYPE OF ORAL } \\
\text { LESION,DISTRIBUTION }\end{array}$ & $\begin{array}{c}\text { SAMPLE } \\
\text { COLLECTION }\end{array}$ & METHODOLOGY & $\begin{array}{c}\text { UP } \\
\text { REGULATION/DOWN } \\
\text { REGULATION }\end{array}$ & $\begin{array}{l}\text { Sensitivity, } \\
\text { specificity, } \\
\text { ROC }\end{array}$ & CONCLUSION \\
\hline $\begin{array}{c}\text { Elisabet } \\
\text { Nylander } e t \\
\text { al, 2012, } \\
\text { Journal of } \\
\text { Oral } \\
\text { Pathology } \\
\text { and } \\
\text { Medicine, } \\
\text { Sweden }\end{array}$ & $\begin{array}{l}\text { miRNA } \\
151-5 P \\
\text { miRNA- } \\
223 \\
\text { miRNA- } \\
143\end{array}$ & $\begin{array}{c}\text { Multifocal mucosal oral } \\
\text { lichen planus CASE:30 } \\
\text { CONTROL:8 }\end{array}$ & Not mentioned & $\begin{array}{c}\text { RT-Qper } \\
\text { MiRCURYLNA } \\
\text { Universal synthesis } \\
\text { kit }\end{array}$ & $\begin{array}{c}\mathrm{P}<0.005 \\
\text { miRNA 151-5P } \\
\text { miRNA-21 } \\
\text { miRNA-223 } \\
\text { miRNA-143 } \\
\text { Were upregulated }\end{array}$ & $\begin{array}{c}\text { Not } \\
\text { mentioned }\end{array}$ & $\begin{array}{l}\text { miRNA plays } \\
\text { an important } \\
\text { role in earlier } \\
\text { stages of OLP }\end{array}$ \\
\hline
\end{tabular}


Table 3: Data extraction form for included study on salivary miRNA 21

\begin{tabular}{|c|c|c|c|c|c|c|c|}
\hline $\begin{array}{l}\text { AUTHOUR, } \\
\text { YEAR AND } \\
\text { COUNTRY }\end{array}$ & MiRNA & $\begin{array}{l}\text { TYPE OF } \\
\text { ORAL } \\
\text { LESION }\end{array}$ & $\begin{array}{c}\text { SAMPLE } \\
\text { COLLECTION }\end{array}$ & METHODOLOGY & $\begin{array}{c}\text { UP } \\
\text { REGULATION/DOWN } \\
\text { REGULATION }\end{array}$ & SENSITIVITY,SPECIFICITY,ROC & CONCLUSION \\
\hline $\begin{array}{l}\text { Zahran et } \\
\text { al., 2015, } \\
\text { Oral } \\
\text { Diseases, } \\
\text { Arab }\end{array}$ & $\begin{array}{l}\text { miRNA- } \\
145,184\end{array}$ & $\begin{array}{l}\text { OPMD without } \\
\text { dysplasia, } \\
\text { OPMD with } \\
\text { dysplasia, } \\
\text { OSCC, } \\
\text { Recurrent } \\
\text { Aphthous } \\
\text { Stomatitis(RAS) } \\
\text { 20- Healthy } \\
\text { control } \\
\text { 20- OPMD } \\
\text { without dysplasia } \\
\text { 20- OPMD with } \\
\text { dysplasia, } \\
\text { 20- OSCC } \\
\text { 20- RAS }\end{array}$ & $\begin{array}{c}\text { Salivary whole } \\
\text { unstimulated } \\
\text { samples were } \\
\text { collected from a } \\
\text { study group of } 100 \\
\text { subjects, consisting } \\
\text { of } 20 \text { clinically } \\
\text { healthy controls, } 40 \\
\text { patients with } \\
\text { OPMDs [20 with } \\
\text { dysplastic lesions } \\
\text { and } 20 \text { without } \\
\text { dysplasia], } 20 \text { with } \\
\text { biopsy-confirmed } \\
\text { OSCC and } 20 \text { with } \\
\text { RAS as disease } \\
\text { controls }\end{array}$ & $\begin{array}{c}\text { Total RNA was } \\
\text { isolated and } \\
\text { purified from } \\
\text { saliva samples } \\
\text { using the } \\
\text { microRNA } \\
\text { Isolation Kit } \\
\text { (Qiagen, UL). } \\
\text { miRNA expression } \\
\text { analysis was } \\
\text { performed using } \\
\text { qRT-PCR } \\
\text { (Applied } \\
\text { Biosystems). }\end{array}$ & $\begin{array}{l}\text { miRNA-21,184 were } \\
\text { upregulated } \\
\text { miRNA } 145 \text { was down } \\
\text { regulated }\end{array}$ & $\begin{array}{c}\text { Sensitivity-miRNA 21-65\% } \\
\text { MiRNA 145-60\%,miRNA 184-80\% } \\
\text { Specificity-miRNA 21-65\% } \\
\text { MiRNA 145-70\%,miRNA 184-75\% } \\
\text { ROC-miRNA 21-0.73 } \\
\text { miRNA 145-0.68,miRNA 184-0.86 }\end{array}$ & $\begin{array}{c}\text { Salivary } \\
\text { determination } \\
\text { of the miRNAs } \\
\text { tested might } \\
\text { furnish a } \\
\text { noninvasive, } \\
\text { rapid } \\
\text { adjunctive aid } \\
\text { for revealing } \\
\text { malignant } \\
\text { transformation } \\
\text { in oral mucosal } \\
\text { lesions, } \\
\text { particularly } \\
\text { miRNA184 }\end{array}$ \\
\hline
\end{tabular}

Table 4: Data extraction for combination of included study done on saliva, serum, tissue miRNA 21

\begin{tabular}{|c|c|c|c|c|c|c|c|}
\hline $\begin{array}{l}\text { AUTHOUR, } \\
\text { YEAR AND } \\
\text { COUNTRY }\end{array}$ & MiRNA & $\begin{array}{l}\text { TYPE OF } \\
\text { ORAL } \\
\text { LESION }\end{array}$ & SAMPLE COLLECTION & $\underset{\mathbf{Y}}{\text { METHODOLOG }}$ & $\begin{array}{l}\text { UP REGULATION/DOWN } \\
\text { REGULATION }\end{array}$ & $\begin{array}{c}\text { SENSITIVI } \\
\text { T, } \\
\text { SPECIFICI } \\
\text { T, ROC }\end{array}$ & CONCLUSION \\
\hline $\begin{array}{c}\text { Cinpolat } \text { et al } \\
\text { in 2017, } \\
\text { Brazilian } \\
\text { Journal of } \\
\text { Otorhinolaryn } \\
\text { gology }\end{array}$ & $\begin{array}{c}\text { miRNA- } \\
23 \mathrm{a}, 27 \mathrm{a}, \\
223,125 \mathrm{~b}, \\
126,146 \mathrm{a} \\
30 \mathrm{e}\end{array}$ & $\begin{array}{c}\text { Salivary } \\
\text { gland } \\
\text { neoplasms } \\
20- \\
\text { Salivary } \\
\text { gland } \\
\text { neplasms } \\
17- \\
\text { Healthy } \\
\text { control }\end{array}$ & $\begin{array}{l}\text { 95microRNAs in the } 20 \text { patients } \\
\text { with salivary gland tumors with } \\
\text { comparison of } 17 \text { patients } \\
\text { without malignancy or salivary } \\
\text { gland diseases. Sixteen of the } \\
\text { tumors were benign (seven } \\
\text { pleomorphic adenomas, nine } \\
\text { Warthin tumors), four of them } \\
\text { were malignant (two squamous } \\
\text { cell carcinomas, one high grade } \\
\text { mucoepidermoidcarcinoma, one } \\
\text { adenocarcinoma. } \\
\text { Serum and saliva samples were } \\
\text { collected from both patients and } \\
\text { control group. Tissue samples of } \\
\text { tumor masses were also collected } \\
\text { from patient group. }\end{array}$ & qRT-PCR & $\begin{array}{c}\text { miRNA-21, 23a,27a,-223, 125b, } \\
126,146 a, 30 \text { were down } \\
\text { regulated in the benign group } \\
\text { compared to control group in } \\
\text { the serum samples (p-values are } \\
0.04,0.00005,0.00005,0.0022, \\
0.031,0.00008,0.044, \text { and } \\
0.0007, \text { respectively) } \\
\text { miRNA30e showed statistically } \\
\text { significant up- } \\
\text { regulation in malignant tumor } \\
\text { group's plasma samples } \\
\text { compared to benign group } \\
(p=0.034)\end{array}$ & $\begin{array}{c}\text { Not } \\
\text { mentioned }\end{array}$ & $\begin{array}{l}\text { Different miRNAs may play role } \\
\text { in salivary tumor pathogenesis } \\
\text { according to biological behavior. } \\
\text { Although there was no difference } \\
\text { in saliva samples between } \\
\text { groups, according to tissue and } \\
\text { serum samples miRNA21 and } \\
\text { 30e may have an important role; } \\
\text { since they were down-regulated } \\
\text { in benign tumors whereas up- } \\
\text { regulated in malignant ones. }\end{array}$ \\
\hline
\end{tabular}


Table 5: Data extraction for included study on saliva and tissue miRNA 21

\begin{tabular}{|c|c|c|c|c|c|c|c|}
\hline $\begin{array}{l}\text { AUTHOUR, } \\
\text { YEAR AND } \\
\text { COUNTRY }\end{array}$ & MiRNA & $\begin{array}{c}\text { TYPE } \\
\text { OF } \\
\text { ORAL } \\
\text { LESION }\end{array}$ & $\begin{array}{c}\text { SAMPLE } \\
\text { COLLECTION }\end{array}$ & METHODOLOGY & $\begin{array}{l}\text { UP REGULATION/DOWN } \\
\text { REGULATION }\end{array}$ & SENSITIVITY,SPECIFICITY,ROC & CONCLUSION \\
\hline $\begin{array}{c}\text { Hung et al } \\
\text { in 2016,Oral } \\
\text { Oncology, } \\
\text { Taipei, } \\
\text { Taiwan }\end{array}$ & $\begin{array}{l}\text { miRNA- } \\
31\end{array}$ & $\begin{array}{c}\text { OPMD } \\
\text { 20-saliva } \\
\text { samples } \\
\text { 46-tissue } \\
\text { samples }\end{array}$ & Not mentioned & qRT-per & $\begin{array}{c}\text { Significantly increased } \\
\text { salivary miRNA21, 31 expression } \\
(\mathrm{P}=0.003 \text { and } \mathrm{P}<0.001, \text { respectively) } \\
\text { was observed in patients with OPMD } \\
\text { compared to control individuals. } \\
\text { Patients with recurrent OPMD } \\
\text { and/or malignant transformation } \\
\text { exhibited a further augmented } \\
\text { expression of miRNA 31, but } \\
\text { not miRNA 21, in the epithelium. } \\
\text { Furthermore, increased miRNA } 31 \\
\text { expression as well as epithelial } \\
\text { dysplasia is an independent risk } \\
\text { factor for OPMD progression as } \\
\text { demonstrated in Cox-proportional } \\
\text { hazard model (HR: } 8.43, P<0.05, \\
95 \% \mathrm{CI}: 1.04 \text { to } 68.03 \text { ) }\end{array}$ & $\begin{array}{c}\text { Sensitivity } \\
\text { MiRNA 21-100\% } \\
\text { MiRNA 31-100\% } \\
\text { Specificity } \\
\text { MiRNA 21-100\% } \\
\text { MiRNA 31-100\% } \\
\text { ROC } \\
\text { MiRNA 21-0.74 } \\
\text { MiRNA 31-0.769 }\end{array}$ & $\begin{array}{c}\text { Salivary miRNA } 21 \text { and } \\
\text { miRNA31 are applicable } \\
\text { as useful OPMD } \\
\text { screening tools. Epithelial } \\
\text { dysplasia and miRNA31 } \\
\text { up-regulation } \\
\text { synergistically predict the } \\
\text { increased incidence of } \\
\text { recurrence and/or } \\
\text { malignant transformation } \\
\text { in patients with OPMD. } \\
\text { Detection of miRNA31 } \\
\text { expression is an adjuvant } \\
\text { method for screening of } \\
\text { high-risk OPMD }\end{array}$ \\
\hline
\end{tabular}

Table 6: Data extraction form for included studies done on cell line and tissue miRNA 21

\begin{tabular}{|c|c|c|c|c|c|c|c|}
\hline $\begin{array}{l}\text { AUTHOUR, } \\
\text { YEAR AND } \\
\text { COUNTRY }\end{array}$ & MiRNA & $\begin{array}{l}\text { TYPE OF } \\
\text { ORAL } \\
\text { LESION } \\
\text { DISTRIBU } \\
\text { TION }\end{array}$ & $\begin{array}{c}\text { SAMPLE } \\
\text { COLLECTIO } \\
\mathbf{N}\end{array}$ & $\begin{array}{l}\text { METHODO } \\
\text { LOGY }\end{array}$ & $\begin{array}{c}\text { UP } \\
\text { REGULATION/D } \\
\text { OWN } \\
\text { REGULATION }\end{array}$ & $\begin{array}{c}\text { SENSITIVITY, } \\
\text { SPECIFICITY, ROC }\end{array}$ & CONCLUSION \\
\hline $\begin{array}{l}\text { Zheng } \text { et al., 2016, } \\
\text { Journal of } \\
\text { molecular medicine } \\
\text { Guangdong, China }\end{array}$ & Nil & $\begin{array}{c}\text { OSCC, } \\
\text { Distributio } \\
\text { n not } \\
\text { mentioned }\end{array}$ & Not mentioned & $\begin{array}{c}\text { Not } \\
\text { mentioned }\end{array}$ & Up regulated & Not mentioned & $\begin{array}{l}\text { The role of MYCN/miRNA 21/CADM1 axis in } \\
\text { chemo-resistance in TC patients and may lead } \\
\text { to promising prognostic biomarkers and novel } \\
\text { treatment strategies to improve the } \\
\text { chemotherapeutic efficacy for TC patients }\end{array}$ \\
\hline $\begin{array}{l}\text { Ren et al., 2014, } \\
\text { Molecular and } \\
\text { Cellular } \\
\text { biochemistry, } \\
\text { Shaanxi, China }\end{array}$ & Nil & $\begin{array}{c}\text { OSCC, } \\
\text { Distributio } \\
\text { n not } \\
\text { mentioned }\end{array}$ & Not mentioned & RT-PCR & Up regulated & Not mentioned & $\begin{array}{l}\text { miRNA } 21 \text { could modulate chemosensitivity of } \\
\text { TSCC cells to cisplatin by targeting PDCD4, } \\
\text { and miRNA } 21 \text { may serve as a potential target } \\
\text { for TSCC therapy }\end{array}$ \\
\hline $\begin{array}{c}\text { Patricia et al., 2010, } \\
\text { Molecular Cancer, } \\
\text { North America }\end{array}$ & Nil & $\begin{array}{c}\text { OSCC, } \\
\text { 50-OSCC } \\
\text { Tissues } \\
\text { 25-Normal } \\
\text { tissues }\end{array}$ & $\begin{array}{l}\text { Tissue samples } \\
\text { were obtained } \\
\text { at time of } \\
\text { surgery of } 50 \\
\text { OSCC patients }\end{array}$ & QPCR & Up regulated & Not mentioned & $\begin{array}{l}\text { PDCD4 may be a clinically relevant } \\
\text { biomarker with prognostic value. PDCD4 loss } \\
\text { may be one of the crucial steps required for } \\
\text { invasion and metastasis of OSCC. In addition, } \\
\text { our data also suggest that PDCD4 under- } \\
\text { expression in OSCC may be regulated by } \\
\text { miRNA21. }\end{array}$ \\
\hline
\end{tabular}


Table 7: Data extraction for included study done on serum and tissue miRNA 21

\begin{tabular}{|c|c|c|c|c|c|c|c|}
\hline $\begin{array}{l}\text { AUTHOUR, } \\
\text { YEAR AND } \\
\text { COUNTRY }\end{array}$ & MiRNA & $\begin{array}{c}\text { TYPE } \\
\text { OF } \\
\text { ORAL } \\
\text { LESION }\end{array}$ & $\begin{array}{c}\text { SAMPLE } \\
\text { COLLECTION }\end{array}$ & METHODOLOGY & $\begin{array}{c}\text { UP } \\
\text { REGULATION/DOWN } \\
\text { REGULATION }\end{array}$ & SENSITIVITY,SPECIFICITY,ROC & CONCLUSION \\
\hline $\begin{array}{c}\text { Ren et al., 2014, } \\
\text { Biomarkers, } \\
\text { Shaanxi, China }\end{array}$ & Nil & $\begin{array}{c}\text { OSCC } \\
10 \\
\text { OSCC } \\
\text { patients }\end{array}$ & Not mentioned & Real time RT-PCR & Up regulated & $\begin{array}{c}\text { Sensitivity62.1\%, } \\
\text { specificity90.6\%, } \\
\text { ROC } \\
0.788\end{array}$ & $\begin{array}{l}\text { Blood miRNA } 21 \text { and PTEN had } \\
\text { significant diagnostic value for } \\
\text { OSCC and, to an extent, correlated } \\
\text { with the expression level of tumour } \\
\text { miRNA } 21 \text { and PTEN. In addition, } \\
\text { they were associated with } \\
\text { differentiation and nodal status. } \\
\text { Thus circulating miRNA } \\
21 \text { and PTEN } \\
\text { might represent new } \\
\text { complementary tumour markers } \\
\text { for OSCC }\end{array}$ \\
\hline
\end{tabular}




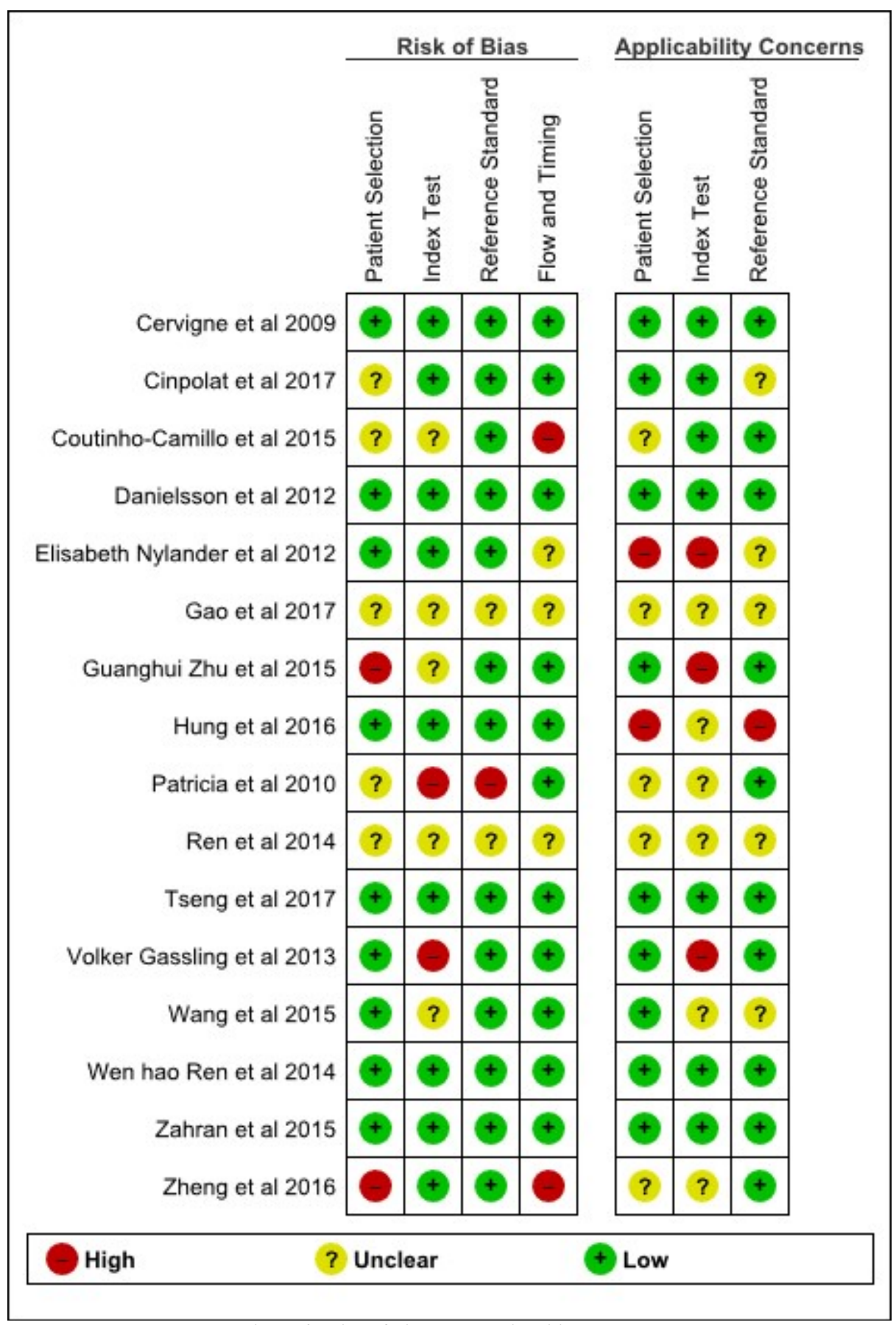

Figure 2: Risk of bias and applicability concern 


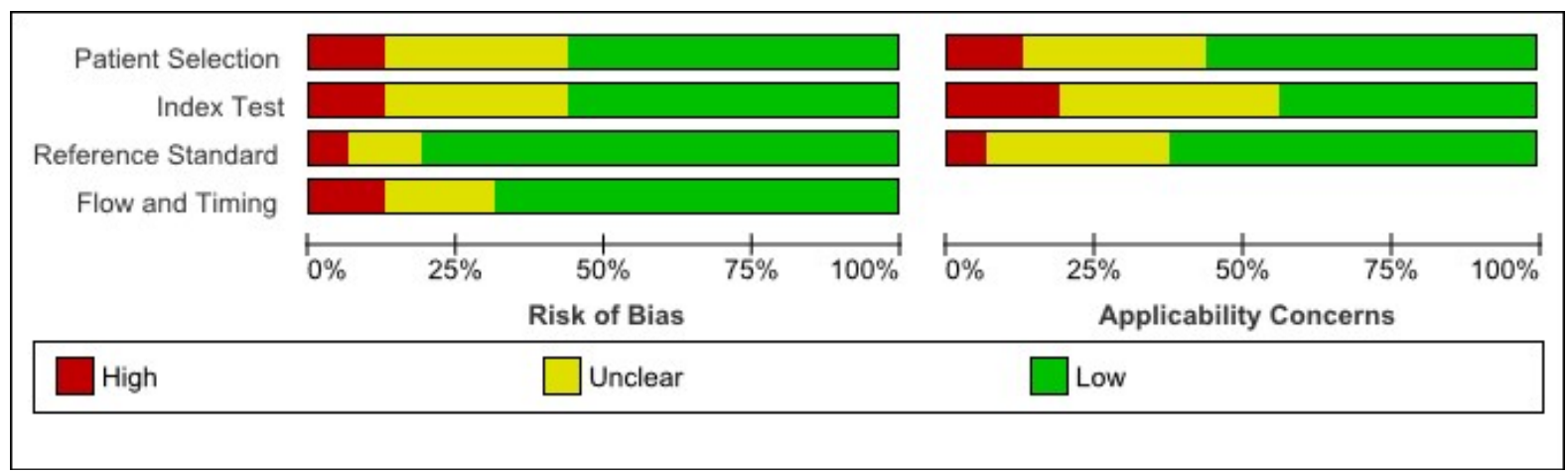

Figure 3: Summary of Risk of bias and Applicability of all sixteen studies

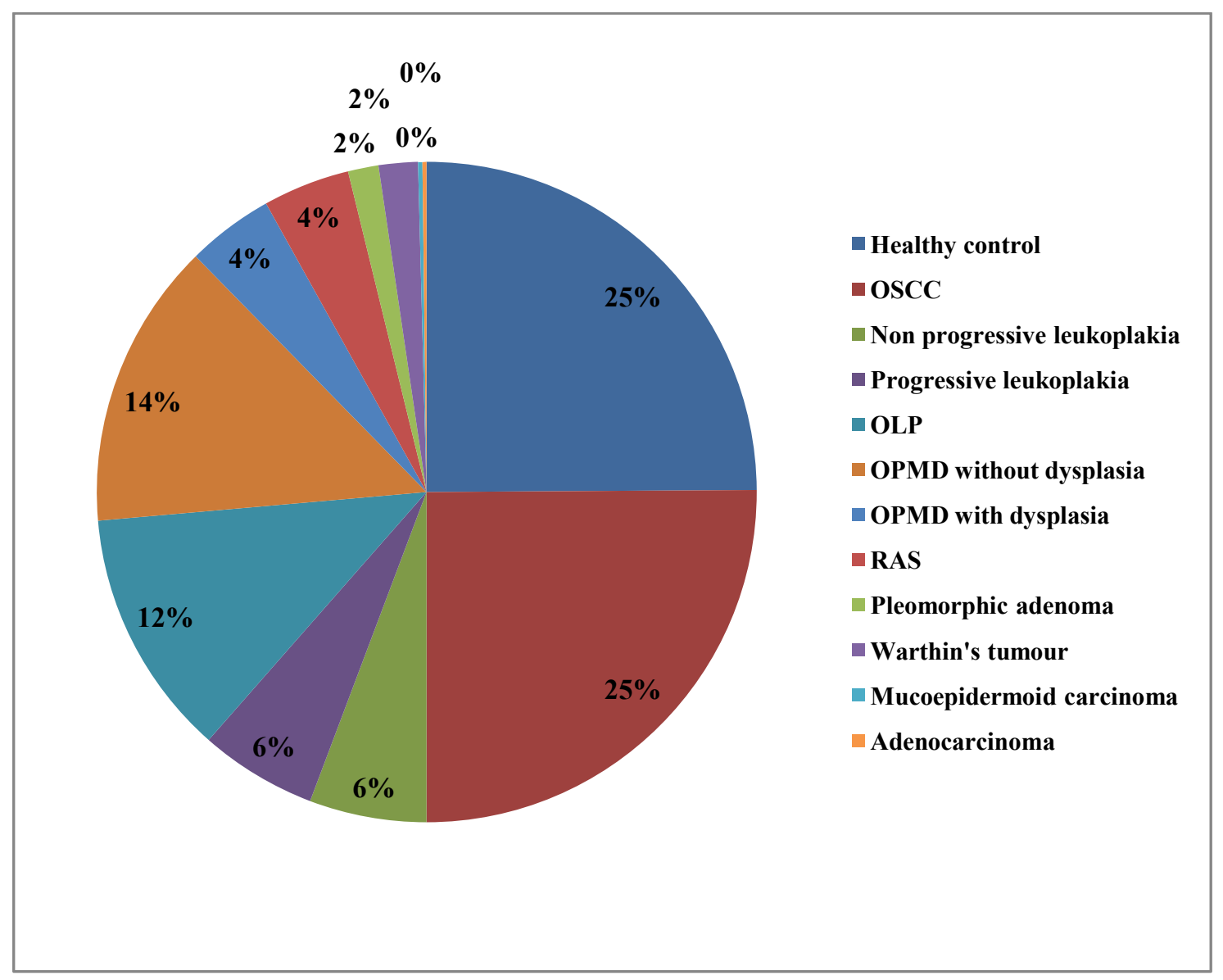

Figure 4: Sample distribution for saliva, serum\& tissue miRNA 21 


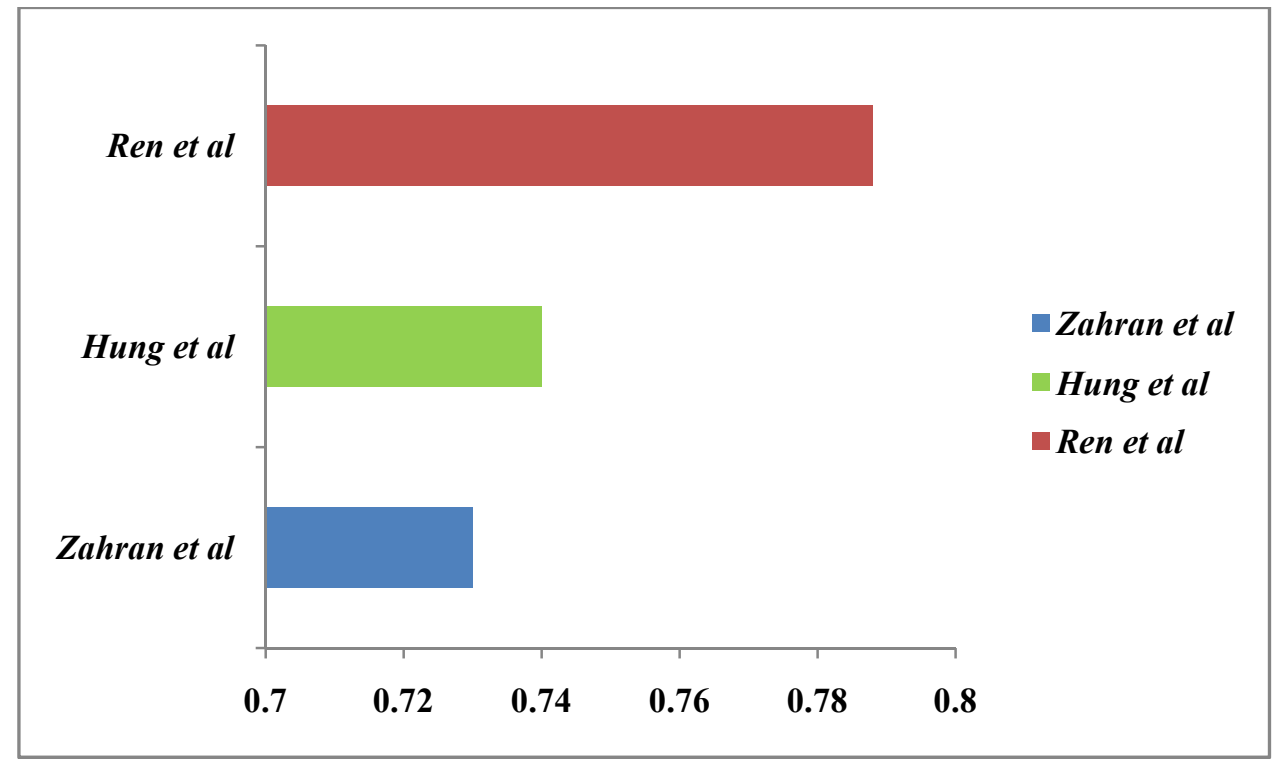

Figure 5: AUC for miRNA 21 as done by different included studies

\section{DISCUSSION}

Studies on circulating and exosomal miRNAs have revealed the diagnostic potential of these mi RNAs as a very useful biomarker in detecting early dysplastic changes in OPMD for an early intervention. The studies considered in this Systematic Review focuses on a combination of salivary, serum and tissue miRNA 21 , to evaluate its expression whether it is upregulated or down regulated in OPMD as well as oral carcinoma. A study on the identification of a miRNA signature associated with progression of leukoplakia to oral carcinoma by Cervigne et al in 2009 revealed that miRNA21 expression was upregulated and associated with increase in lesion severity during progression [19]. In a case control study done by CoutinhoCamillo et al in 2015 on the expression of apoptosis regulating miRNAs (miRNA$15 \mathrm{a}, 16,17-5 \mathrm{p}, 20 \mathrm{a}, 21,29 \mathrm{a}, 34 \mathrm{a})$ in OSCC, it was found that miRNA21 expression was found to be normal. BCL2, CASP2, CASP7, CASP8, DIABLO were found to be the common target genes for the studied miRNAs [20]. A study done by Danielsson et al in 2012 on the expression of miRNA21, 125b, 203 to p53 and p63 levels, it was found to be negatively correlated and miRNA 21 was found to be over expressed in cases of Oral lichen planus [21]. Elisabeth Nylander et al in 2012 evaluated the changes in miRNA expression in sera and their correlation to the duration of disease in patients with multifocal mucosal lichen planus, found that miRNA 21 was upregulated and its important role in early stages of progression of OLP [22]. Gao et al in 2017 studied the expression of PTENp1, a natural sponge of miRNA21, mediating via PTEN in the inhibition of the proliferation of OSCC and they found that PTENp1 acted as a competing endogenous 
RNA and protected PTEN transcripts from being inhibited by miRNA21, and consequently inhibited proliferation and colony formation and triggered S-G2/M cell cycle arrest through the AKT pathway [23]. Study by Guanghui Zhu et al in 2015 proved that apart from essential hub genes, inter MAO genes, the upregulation of miRNA 21 is essential in the malignant transformation of leukoplakia [24]. A study done by KF Hung et al in 2016 on miRNA31 upregulation in OPMD revealed significantly increased salivary miRNA21 and miRNA31 expression in OPMD patients compared to healthy controls. The sensitivity was $100 \%$ for both miRNA 21 and microRNA 31, AUC was 0.769 for miRNA 31 and 0.74 for miRNA 21 [25]. In a study done by Patricia et al in 2010 they found that programmed cell death 4 loss increases tumor cell invasion and was regulated by miRNA21 in OSCC [26]. Ren et al in 2014 found that circulating miRNA 21 and PTEN might represented as new complementary tumour markers for OSCC [27]. In another study done by Ren W et al in 2014 revealed that miRNA21 modulated chemosensitivity of TSCC cells to cisplatin by targeting PDCD4, and proved that miRNA21 served as a potential target for TSCC therapy [28]. Tseng et al in 2017 found that miR-21-3p played a crucial oncogenic role in cell metastasis during OSCC progression [29]. Volker Gassling et al in 2013 found that miRNA was associated with transcripts which were regulated when comparing OLP patients with healthy control individuals. This suggested that miRNAs potentially regulated disease-relevant transcripts [30]. A study done by Wang et al in 2015 found that combination of cisplatin application with miRNA21 downregulation served as a potential target for the therapy of OSCC [31]. A study done by Zahran et al in 2015 on salivary miRNAs in oral cancer revealed a significant increase in miRNA21, miRNA184 in OSCC and OPMD. $(\mathrm{P}<0.001)$ miRNA145 showed a significant decrease in OSCC and OPMD $(\mathrm{P}<0.001)$. Diseased controls with Recurrent Aphthous Stomatitis (RAS) did not show any statistical significant difference from normal controls $(\mathrm{P}>0.05) \mathrm{ROC}$ curve revealed cutoff points delineating the occurrence of malignant change with a fourfold increase with specificity $65 \%$ and sensitivity $65 \%, 0.6$ decrease in miRNA 145 with specificity $70 \%$ and sensitivity $60 \%$ and a threefold increase of miRNA184 with specificity $75 \%$ and sensitivity $80 \%$ [32]. Study done by Zheng et al in 2016 suggested the role of MYCN/miRNA21/CADM1 axis in chemoresistance in TC patients [33]. A case control study done by Cinpolat et al in 2017 on the comparison of miRNA profiles between benign and malignant salivary 
gland tumours in tissue, blood and saliva samples, it was found that miRNA21 and miRNA30e were upregulated in the malignant salivary gland tumour and down regulated in the benign group. RPS7 and LIMCH1 were the common target genes for those miRNAs [34].

Five studies had low risk of bias had compared the disease control (OPMD with dysplasia, OPMD without dysplasia, Oral Lichen Planus (OLP), RAS, OSCC had proved to have statistically significant results. These 16 studies were done in Canadian, Chinese, Brazilian, Taiwan, North American, Swedish, German and Arabic populations.

In consideration to the AUC curve (Figure 4) for miRNA 21, study by Zahran et al had low risk of bias had predetermined a cut off value for the miRNA before the onset of the study and AUC was 0.73. According to this study miRNA 184 is the marker with maximum sensitivity and specificity. The same study has also reported that upregulated miRNA 21 and down regulated miRNA 145 are markers for detecting OPMD with dysplasia, OPMD without dysplasia and OSCC. Study by KF Hung et al had AUC 0.74 with a predetermined cut off value, while AUC for miRNA 21 done by Ren et al in 2014 was 0.788 which suggested the overall AUC for miRNA 0.75 .

\subsection{FUTURE RECOMMENDATIONS FOR RESEARCH}

A long term follow-up with minimal risk of bias in patient selection and comparison with reference standard is essential for the long term success of the potential role of miRNA 21 in detecting early dysplastic changes in cases of OPMD before it progresses to malignancy. There were more number of studies done in tissue miRNA 21 compared to studies on salivary and tissue miRNA 21 proving the need for more research studies on salivary and serum miRNA 21 for the long term efficiency and the vital need for miRNA 21 as a potential biomarker in OPMD and oral cancer.

\section{CONCLUSION}

According to literature, miRNA 21 proves to be a very useful diagnostic tool serving as a potential biomarker in saliva, serum and tissue samples of OPMD patients as a screening tool for detecting early malignant changes which aids for earlier intervention before it progresses to carcinoma. Of the thirteen studies for tissue miRNA 21, only one study was statistically significant with sensitivity, specificity and ROC. Likewise with three studies each for serum and salivary miRNA 21 , only one each had mentioned sensitivity, specificity and ROC which indicates the need for more statistically proven studies in the future. Based on the statistical analysis of sensitivity, specificity, ROC it was found 
that one study on tissue miRNA 21 had ROC of 0.74 , a study on serum miRNA 21 had ROC of 0.788 and study on salivary miRNA 21 revealed an ROC of 0.73 . On taking into account the ROC of the included studies it was found to be consistent with an average of 0.75 which indicates that serum, tissue and saliva all are consistent and they serve as optimal media for the identification of miRNA 21 and even other miRNAs in cases of OPMD and OSCC. Since collection of saliva is a non invasive method compared to serum or tissue, this systematic review proves that saliva is a surrogate marker for the identification of miRNA 21 in OPMD and oral cancer.

\section{ACKNOWLEDGEMENT}

Department of Oral Medicine and Radiology, Saveetha Dental College, Saveetha University.

\section{SOURCE OF FUNDING}

Not applicable

\section{REFERENCES}

[1] Chi Han Li and Yangchao Chen. Small and Long Non-Coding RNAs. 2015. Novel Targets in Perspective Cancer Therapy. Current Genomics. 16(5): 319-326.

[2] Andrei Zinovyev et al. Dynamical modeling of microRNA action on the protein translation process. 2010 BMC Systems Biology. 4: 13.
[3] Lee P. Lim et al. The microRNAs of Caenorhabditis elegans. 2003. Genes and Development. 17(8): 991-1008.

[4] Caitlin Sedwick. Victor Ambros: The broad scope of microRNAs. 2013. Journal of Cell Biology. 201(4): 492-493.

[5] Zhen Shetal. Dual Regulation of the lin-14 Target mRNA by the lin4 miRNA.2013 Journal of PLOS. 8(9): e75475.

[6] Hosuk Lee et al. Biogenesis and regulation of the let-7 miRNAs and their functional implications.2016 Protein and Cell. 7(2): 100-113.

[7] Wan J. Hsieh et al. Investigating microRNA-Target InteractionSupported Tissues in Human Cancer Tissues Based on miRNA and Target Gene Expression Profiling. 2014. PLoSOne. 9(4): e95697.

[8] Medina PP et al. Oncomi $\mathrm{R}$ addiction in an in vivo model of microRNA-21-induced pre-B-cell lymphoma. 2010. Nature. 467 (7311): 86-90.

[9] Carlo M. Croce, M.D. Causes and consequences of microRNA dysregulation in cancer. 2009. Nature Reviews and Genetics. 10(10): 704-714. 
[10] Li Ma. Role of miR-10b in breast cancer metastasis.2010 Breast Cancer Research. 12(5): 210.

[11] Tsutomu Kawaguchi et al. Overexpression of suppressive microRNAs, miR-30a and miR200c are associated with improved survival of breast cancer patients. 2017. Scientific Reports. 7. 15945.

[12] Minal Garg. MicroRNAs, stem cells and cancer stem cells. 2012. World Journal of Stem Cells. 4(7): 62-70.

[13] Martin D. Jansson et al. MicroRNA and cancer. 2012. Oral Oncology. 6(6): 590-610.

[14] Zhiyun Guo et al. Genome-wide survey of tissue-specific microRNA and transcription factor regulatory networks in 12 tissues. 2014. Scientific Reports. 4: 5150.

[15] Manish Bhomia et al. A Panel of Serum MiRNA Biomarkers for the Diagnosis of Severe to Mild Traumatic Brain Injury in Humans. 2016 Scientific Reports. 6: 28148 .

[16] Dr. Yu-Hsiang Lee et al. Saliva: Anemerging biofluid for early detection of diseases. 2009. American Journal of Dentistry. 22(4): 241-248.
[17] Ali M. Ardekani and Mozhgan Moslemi Naeini. The Role of MicroRNAs in Human Diseases.2010. Avicenna Journal of Medical Biotechnology. 2(4): 161-179.

[18] Lindsey E. Becker Buscaglia and Yong Li. Apoptosis and the target genes of microRNA-21.2011. Chinese Journal of Cancer. 30(6): 371-380.

[19] Cervigne NK et al. Identification of a microRNA signature associated with progression of leukoplakia to oral carcinoma. 2009. Hum Mol Genet. 18(24): 4818-29.

[20] Coutinho-Camillo CM, Lourenço SV, de Araújo Lima L, Kowalski LP, Soares FA. Expression of apoptosis-regulating miRNAs and target mRNAs in oral squamous cell carcinoma. 2015. Cancer Genet. 208(7-8): 382-9.

[21] Danielsson K, Wahlin YB, Gu X, Boldrup L, Nylander K. Altered expression of miR-21, miR-125b, and miR-203 indicates a role for these microRNAs in oral lichen planus. 2012. J. Oral Pathol Med. 41(1): 90-5.

[22] Nylander E, Ebrahimi M, Wahlin YB, Boldrup L, Nylander K. Changes in miRNA expression in 
sera and correlation to duration of disease in patients with multifocal mucosal lichen planus. 2012. J Oral Pathol Med. 41(1): 86-9.

[23] Gao L, Ren W, Zhang L, Li S, Kong X, Zhang H, Dong J, Cai G, Jin C, Zheng D, Zhi K.PTENp1, a natural sponge of miR-21, mediates PTEN expression to inhibit the proliferation of oral squamous cell carcinoma. 2017. Mol Carcinog. 56(4): 1322-1334.

[24] Guanghui Zhu et al. Identification of Gene and MicroRNA Signatures for Oral Cancer Developed from Oral Leukoplakia. 2015. Biomed Res Int. 841956.

[25] Hung KF et al. MicroRNA-31 upregulation predicts increased risk of progression of oral potentially malignant disorder. 2016. Oral Oncol. 53: 42-7.

[26] Reis PP, Tomenson M, Cervigne NK, Machado J, Jurisica I, Pintilie M, Sukhai MA, Perez-Ordonez B, Grénman R, Gilbert RW, Gullane PJ, Irish JC, Kamel-Reid S. Programmed cell death 4 loss increases tumor cell invasion and is regulated by miR-21 in oral squamous cell carcinoma. 2010. Mol Cancer. 9: 238.

[27] Ren W, Qiang C, Gao L, Li SM, Zhang LM, Wang XL, Dong JW,
Chen C, Liu CY, ZhiKQ. Circulating microRNA-21 (MIR21) and phosphatase and tensin homolog (PTEN) are promising novel biomarkers for detection of oral squamous cell carcinoma. 2014. Biomarkers. 19(7): 590-6.

[28] Ren W, Wang X, Gao L, Li S, Yan X, Zhang J, Huang C, Zhang Y, Zhi K.MiR-21 modulates chemosensitivity of tongue squamous cell carcinoma cells to cisplatin by targeting PDCD4. 2014. Mol Cell Biochem. 390 (12): 253-62.

[29] Tseng HH, Tseng YK, You JJ, Kang BH, Wang TH, Yang CM, Chen HC, Liou HH, Liu PF, Ger LP, Tsai KW. Next-generation Sequencing for micro RNA Profiling: $\quad$ MicroRNA-21-3p Promotes Oral Cancer Metastasis. 2017. Anticancer Res. 37(3): 1059-1066.

[30] Volker Gassling et al. DiseaseAssociated miRNA-mRNA Networks in Oral Lichen Planus. 2013. PLoSOne. 8(5): e63015.

[31] Zahran F et al. Salivary microRNAs in oral cancer. 2015. Oral Diseases. 21(6): 739-47.

[32] Wang W, Songlin P, Sun Y, Zhang B, Jinhui W.miR-21 inhibitor sensitizes human OSCC 
cells to cisplatin. 2012. Mol. Biol Rep. 39(5): 5481-5.

[33] Zheng G, Li N, Jia X, Peng C, Luo L, Deng Y, Yin J, Song Y, Liu H, Lu M, Zhang Z, Gu Y, He Z.MYCN-mediated miR-21 overexpression enhances chemoresistance via targeting CADM1 in tongue cancer. 2016 J Mol Med (Berl). 94(10): 1129-1141.

[34] Cinpolat $\mathrm{O}$ et al. Comparison of microRNA profiles between benign and malignant salivary gland tumors in tissue, blood and saliva samples: a prospective, case-control study. 2017. Braz. J Otorhinolaryngol. 83(3): 276-28. 